\title{
Synthesis of Graphene Oxide from Hydrogenated Diamond Like Carbon and Protein Immobilization onto It: Characterization and Study of Practical Utility
}

\author{
Subhashis Bala1,2, Reshmi Bose3, Shaona Chaterjee4, Sanjit Sarkar5, Indranil Saha6, \\ Hari Shankar Biswas ${ }^{1^{*}}$ \\ ${ }^{1}$ Department of Chemistry, Surendranath College, Kolkata, India \\ ${ }^{2}$ Darappur High School [H.S], Chakdaha, Nadia, India \\ ${ }^{3}$ Department of Basic Science and Humanities, University of Engineering and Management, Newtown, India \\ ${ }^{4}$ Department of Chemistry, Presidency University, Kolkata, India \\ ${ }^{5}$ Department of Physics, Surendranath Evening College, Kolkata, India \\ ${ }^{6}$ Sripat Singh College, Jiagangj, Murshidabad, West Bengal, India \\ Email: *harishankarb7@gmail.com
}

How to cite this paper: Bala, S., Bose, R., Chaterjee, S., Sarkar, S., Saha, I. and Biswas, H.S. (2021) Synthesis of Graphene Oxide from Hydrogenated Diamond Like Carbon and Protein Immobilization onto It: Characterization and Study of Practical Utility. Journal of Materials Science and Chemical Engineering, 9, 32-41.

https://doi.org/10.4236/msce.2021.91003

Received: October 6, 2020

Accepted: January 26, 2021

Published: January 29, 2021

Copyright ( 2021 by author(s) and Scientific Research Publishing Inc. This work is licensed under the Creative Commons Attribution International License (CC BY 4.0).

http://creativecommons.org/licenses/by/4.0/ (c) (i) Open Access

\begin{abstract}
In the last few years, Graphene oxide material and biomolecules studies have increased. The various synthesis methods of graphene oxide are constantly pursued to improve and provide safer and more effective alternatives. Though the preparation of graphene oxide from Graphite powder or Graphite flake through Hummers method is one of the oldest techniques but still now it is one of the most suitable methods. Here, Graphene Oxide has been prepared from a tunable material Hydrogenated diamond like carbon (HDLC) which is an atomically smooth surface that can be deposited on high-surface area Silicon (100) wafer plate. The HDLC film was heated at a fixed temperature of $900^{\circ} \mathrm{C}$ for $30 \mathrm{~min}$ in high vacuum $\sim 1 \times 10^{-6}$ torr and oxygenated at room temperature. A synthetic sequence is described involving Oxidation of annealed HDLC (A-HDLC). Raman measurements confirm the G and D peak by Oxidation of A-HDLC and FTIR confirms functional groups. Atomic force microscopy (AFM) images describe the surface of A-HDLC, Oxidized Graphene and BSA immobilized GO. This GO onto Silicon substrate offers many technical advantages than as oxidized graphene Synthesis from other Chemical methods.
\end{abstract}

Keywords

Carbon, Diamond, Graphene Oxide, AFM, Raman, FTIR 


\section{Introduction}

Preparation of Graphene Oxide and Immobilization of biomolecules onto the large smooth surface for biosensor applications has attracted significant attention in recent years around the Globe. Besides, immobilization of biomolecules [1] [2] [3] [4] onto surfaces of different material is essential in many fields of Chemical [5] [6], physical, biological sciences, including cell and molecular biology, medical diagnostics, analytical chemistry, tissue engineering, and bioprocess engineering. Since the discovery of the many advantageous properties of immobilized biomolecules, the challenges in this area have been to develop new support substrate materials with appropriate structures, surface morphology and functionality to widen the understanding of immobilized biomolecules. Recently, along with the development of nanostructured materials [7], a range of nanomaterials with different surface properties have been utilized as substrates for biomolecule immobilization [8]. In particular, oxidized graphene [9] has been demonstrated as a well-defined, ordered, and atomically smooth surface [9]. Graphene is comprised of a lattice of carbon atoms in a hexagonal array, creating an ordered structure against which morphology of immobilized biomolecules can be easily discerned. We have demonstrated here that the GO can be prepared from A-HDLC as large solid-state sheets to produce an ordered structure which can be used as a solid support substrate on which biomolecules can be immobilized, spontaneously adsorbed [10].

\section{Abbreviations and Acronyms}

Hydrogenated Diamond Like Carbon (HDLC), Graphene Oxide (GO), Oxidation of annealed HDLC (A-HDLC), Atomic force microscopy (AFM), Bovine Serum Albumin (BSA), BSA treated Graphene oxide sample (BGO), Transmission electron microscopy (TEM), Scanning electron microscopy (SEM).

\section{Materials and Methods}

\subsection{Materials}

Potassium Permanganate (extra pure AR, 99.5\%, Sisco Research Laboratories Pvt. Ltd.), Potassium nitrate, (ACS reagent, $\geq 99.0 \%$, Sigma Aldrich), Sodium Phosphate Dibasic Anhydrous, (99.5\%, Sisco Research Laboratories Pvt. Ltd.), Bovine Serum Albumin (BSA) (96.96\%, Sisco Research Laboratories Pvt. Ltd.). Ultra-pure water using Milli-Q system of Millipore Co. was used throughout the experiment.

\subsection{Preparation Graphene Oxide from HDLC}

We already have demonstrated earlier [11] a straightforward synthesis of HDLC film surfaces. The HDLC film was heated to get Graphene-like and graphite-like structure [12] (A-HDLC) at a fixed temperature of $1000^{\circ} \mathrm{C}$ for 30 min in high vacuum $\sim 1 \times 10^{-6}$ torr and cooled to room temperature after heating. Graphene oxide (GO) was prepared from A-HDLC according to the 
modified Hummers-Offeman method [13]. In brief, about $10 \mathrm{~mm}$ diameter A-HDLC sample was taken in $50 \mathrm{~mL}$ beaker and cold concentrated sulphuric acid added to it ( $1 \mathrm{~mL}, 98 \mathrm{wt} \%$, dry ice bath) and potassium permanganate $\left(\mathrm{KMnO}_{4}, 20 \mathrm{mg}\right)$ gradually added with continuous vigorous stirring and cooling to prevent the temperature from exceeding $25^{\circ} \mathrm{C}$. The dry ice bath was removed and replaced by a water bath and the mixture heated to $35^{\circ} \mathrm{C}$ for half an hour with gas release under continuous stirring, followed by slow addition of deionized water $(2 \mathrm{~mL})$, which produced a rapid increase in solution temperature up to a maximum of $90^{\circ} \mathrm{C}$. The reaction was maintained for $10 \mathrm{~min}$ to increase the oxidation degree of the graphene oxide product.

\subsection{Immobilization of Protein onto the Surface of Graphene Oxide}

0.2 M Phosphate buffers of $\mathrm{pH} 7.5$ were prepared at room temperature. Graphene Oxide sample, cleaned by isopropyl alcohol and rinsed in ultra-pure water, dried with nitrogen and was immersed in BSA solution, prepared by dissolving $25 \mathrm{mg}$ of BSA in $25 \mathrm{~mL}$ of $0.2 \mathrm{M}$ Phosphate buffer, for 2 hours at room temperature under slow stirring was condition using a magnetic stirrer. The BGO was rinsed with ultra-pure water and dried with nitrogen.

\subsection{Characterization of Samples}

The cross sectional view and the morphology of the surface of the GO film surface have been analyzed by TEM, AFM and SEM respectively. Raman spectrum of the GO sample was obtained by the confocal Micro Raman spectrometer (LabRAM $H R$ Vis, Horiba Jobin Yvon SAS France) which includes an $800 \mathrm{~mm}$ focal length Czerny-Turner type spectrograph equipped with mirrors (reflective optics) having high spectral resolution of $0.1 \mathrm{~cm}^{-1} /$ pixel at $488 \mathrm{~nm}$ with an $1800 \mathrm{gr} / \mathrm{mm}$ grating. FTIR spectrum of the sample was obtained by Infrared Fourier Vacuum Spectrometer Vertex 70v (Bruker Optik GmbH Germany) with fixed 30 angle reflection with ATR crystal (Zn-Se) for solid GO sheet and sample. KBr beam splitter, DLaTGS detector, MIR source, Rock Solid Interferometer system, spectral resolution $\left(>0.4 \mathrm{~cm}^{-1}\right)$ and contamination free vacuum $(<0.2 \mathrm{mbar})$ are the key technical features of Vertex $70 \mathrm{~V}$. AFM topography image of the sample was obtained in non-contact mode by Multimode Scanning Probe Microscope (Agilent AFM 5500 series, USA) having multipurpose small scanner with low coherence laser $(1 \mathrm{~mW}$ power, $670 \mathrm{~nm}$ wavelength, length of coherence $(<50 \mathrm{~mm})$, scan range: $X Y$ : $0-10$ mm; Z: 0 - 2 mm, noise level: XY $<0.1$ nm RMS, $Z<0.02$ nm RMS.

\section{Results and Discussion}

Raman spectroscopy is a fingerprint and non-destructive technique to characterize graphitic materials, in particular to determine the defects and the ordered and disordered structures of graphene. Figure 1 shows the Raman spectra of the A-HDLC and GO sheets prepared from HDLC. The Raman spectra of GO sheet display two prominent peaks at 1358 and $1598 \mathrm{~cm}^{-1}$, corresponding to the 
well-documented D- and G-band. The G line represents the in-plane bond stretching motion of the pairs of $\mathrm{C} \mathrm{sp}^{2}$ atoms (the $\mathrm{E}_{2 \mathrm{~g}}$ phonons); while the $\mathrm{D}$ line corresponds to breathing modes of rings or j-point phonons of $A_{1 g}$ symmetry [14]. Usually, the graphene-like sheets synthesized by annealing of HDLC approach show two clear D and G band in the Raman spectrum with the intensity ratio of $\mathrm{ID} / \mathrm{IG} \approx 1$ due to the defects and partially disordered crystal structure of graphene-like sheets. It is noted here that for the GO, the intensity of the G band is significantly higher than that of the $\mathrm{D}$ band, suggesting that the prepared graphene Oxide has low defect content [15] [16]. Figure 2 shows the thickness of the HDLC thin film.

The FT-IR analysis [17] of GO in Figure 3 shows the existence of H-bonded $\mathrm{OH}$ stretch at $3415 \mathrm{~cm}^{-1}, \mathrm{C}-\mathrm{H}$ stretch at $2915 \mathrm{~cm}^{-1}, \mathrm{C}=\mathrm{O}$ in carboxylic acid group at $1725 \mathrm{~cm}^{-1}, \mathrm{C}=\mathrm{C}$ in conjugated ketones at $1628 \mathrm{~cm}^{-1}$ and primary alcohol C-O stretch at $1086 \mathrm{~cm}^{-1}$. The presence of oxygen-containing groups on GO is observed while Graphene-like/Graphite-like spectra have no significant peak for these groups [18] [19]. FTIR analysis [20] [21] [22] in Figure 3 and

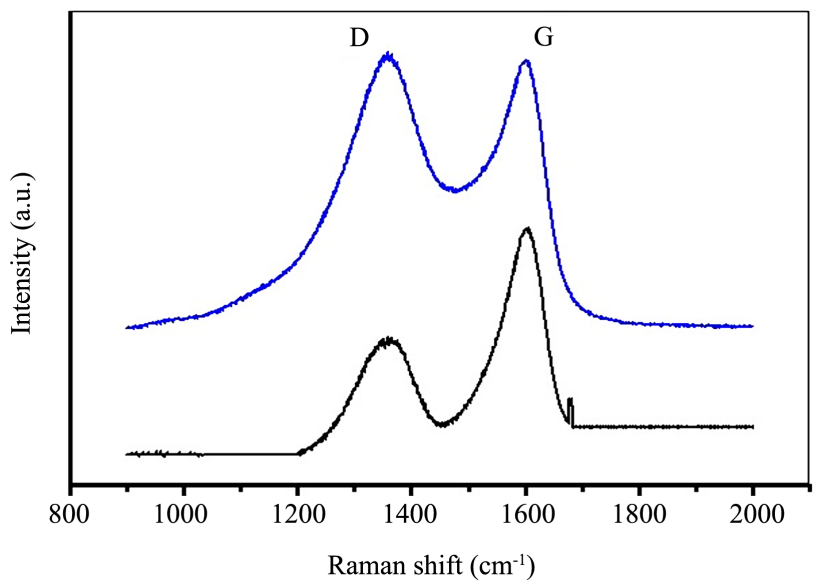

Figure 1. Raman spectra of the A-HDLC and GO sheets prepared from HDLC. (Black = GO, Blue = A-HDLC; Excitation wavelength $488 \mathrm{~nm}$, laser power $7.5 \mathrm{~mW}$, grating 1800 $\mathrm{gr} / \mathrm{mm}$, objective $100 \times$, aperture $100 \mu \mathrm{m}$.

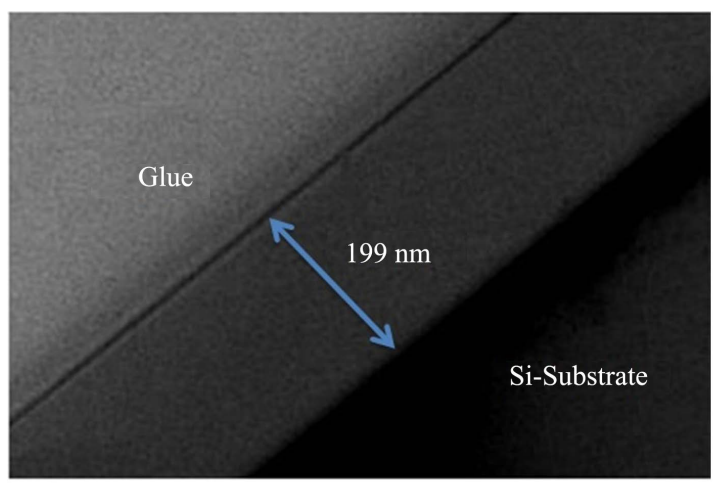

Figure 2. Typical TEM cross sectional view of the GO film measured with a Philips CM200 kV TEM machine operated at $200 \mathrm{kV}$ with LaB6 filament; the sample of the cross section was prepared by the TEM sample preparation equipments of Gatan, USA. 


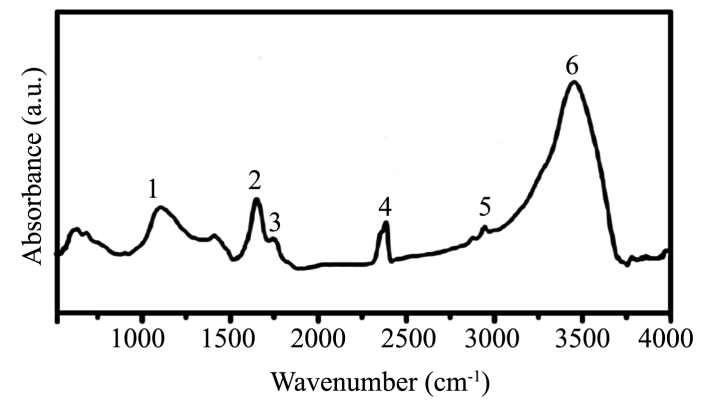

Figure 3. Typical FTIR Spectra of GO sheet sample surface.

Figure 4 revealed that, after immobilization BSA onto GO, the peak intensity of GO at $1725 \mathrm{~cm}^{-1}$ (carboxylic acid), $1628 \mathrm{~cm}^{-1}$ (primary alcohol) and disappeared implying the reaction of such groups in GO. Characteristic peaks [19] [20] [21] [22] of the functional groups present in the GO and BGO samples, as shown in Figure 3 and Figure 4, are assigned, and are given in Table 1(a) and Table 1(b), respectively. Figure 4 shows the immobilization of BSA, where the protein is immobilization on GO based on physical immobilization via $\pi-\pi$ stacking and other molecular interactions. The physical immobilization onto GO occurs via different types of interactions, such as Van der Waals forces, electrostatic or hydrophobic $\pi-\pi$ stacking interactions and hydrogen bonds between the oxygen functional groups of GO and nitrogen/oxygen groups of protein and chemical interaction i.e. covalent bond may among $\mathrm{C}=\mathrm{O}$ of $\mathrm{GO}$ and $-\mathrm{NH}_{2}$ of Protein [23] [24].

Figure 5 and Figure 6 show the SEM images of Graphene-like A-HDLC and GO sheets composites, respectively. The sample shows plate-like forms without any amorphous or other kinds of crystallized phase particles. Morphology of GO [25] [26] is observed as flaky texture reflecting its layered microstructure as shown in Figure 6. The larger interspaces of the layer and the thinner layer edges of GO can be clearly seen in Figure 6.

AFM was employed to characterize the degree of exfoliation of graphene-like sheets. As shown in Figure 7, a flat graphene-like sheet was selected for further investigation using the three-dimensional view.

From the profile of the atomic force microscopy (AFM) image, the roughness of the GO film in the GO device was estimated to be approximately $10 \mathrm{~nm}$. We performed AFM to investigate the morphology of the GO sheets (Figure 8). The well-ordered surface improves resolution of immobilized protein by AFM. The root mean square roughness was $0.1 \mathrm{~nm}$. It seemed that whole area was covered with GO sheets. We have shown that GO can serve as a substratum for immobilization of proteins. Since BSA protein is a complex molecule having a large variety of functional groups, at this stage it is very difficult to identify the exact route of reaction pathways for GO sheets with BSA protein. There were two reactive groups namely $\mathrm{C}=\mathrm{O}$ and $-\mathrm{OH}$ groups in $\mathrm{GO}$ sheets. The more possibility for the reaction of BSA protein with GO sheets is electrostatic interaction/H-bonding/Vander waal's force of attraction and covalent bonding. The 


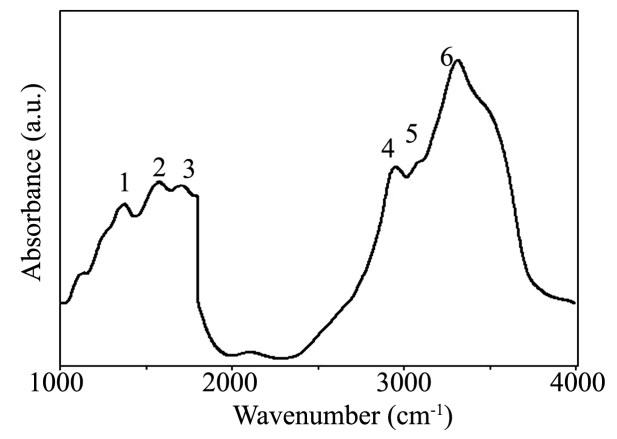

Figure 4. Typical FTIR Spectra of BGO sheet sample surface.

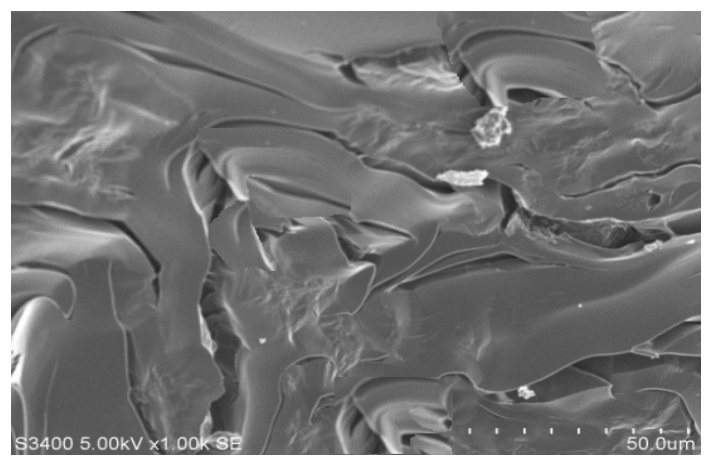

Figure 5. SEM image of Graphite-like sheet (A-HDLC) and Graphene-like sheet.

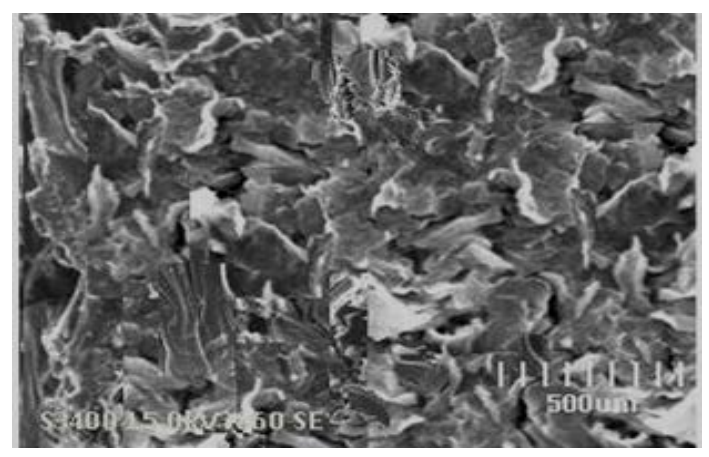

Figure 6. SEM image of GO sheets.

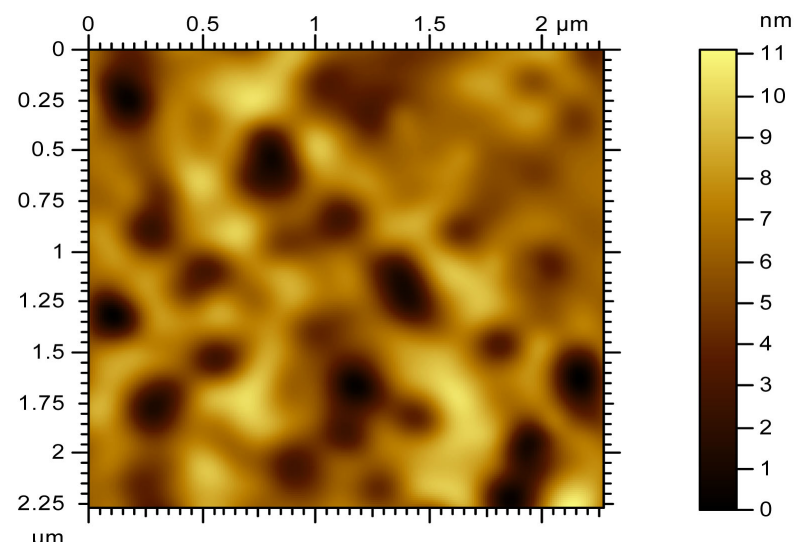

Figure 7. Non-contact mode AFM topography images of A-HDLC surface: scan size 2.25 $\mu \mathrm{m} \times 2.25 \mu \mathrm{m}$. 


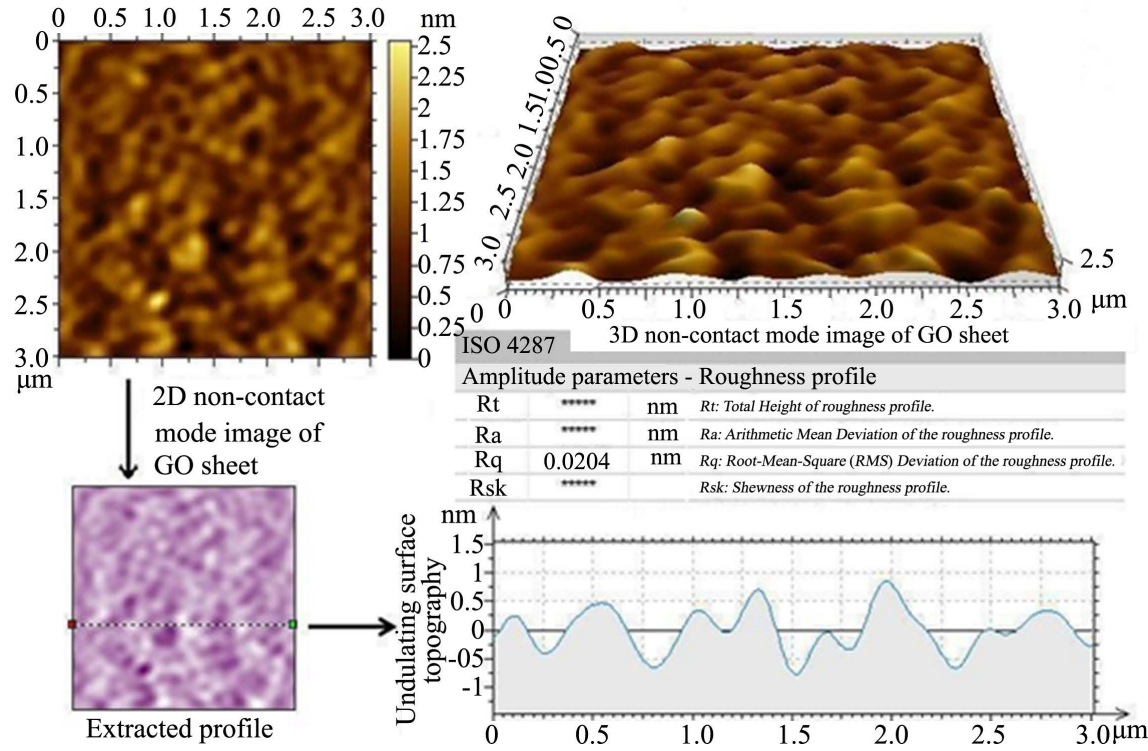

Figure 8. Non-contact mode 2D and 3D AFM topography images of GO sheets: scan size $3 \mu \mathrm{m} \times 3 \mu \mathrm{m}$.

Table 1. (a) Tentative assignments of peaks in the FTIR spectra of GO sheet; (b) Tentative assignments of peaks in the FTIR spectra of BGO.

(a)

\begin{tabular}{ccc}
\hline $\begin{array}{c}\text { Peak } \\
\text { No. }\end{array}$ & $\begin{array}{c}\text { Wave number } \\
\left(\mathrm{cm}^{-1}\right)\end{array}$ & Tentative assignment \\
\hline 1 & 1086 & $\mathrm{C}-\mathrm{O}$ stretching \\
2 & 1628 & $\mathrm{C}=\mathrm{C}$ stretching \\
3 & 1725 & $\mathrm{C}=\mathrm{O}$ \\
4 & 2362 & $\mathrm{CO}_{2}$ stretching \\
5 & $2825-3050$ & Aliphatic and Aromatic C-H stretching \\
6 & $3100-3600$ & Broad band for O-H stretching and H-bonding \\
\hline
\end{tabular}

(b)

\begin{tabular}{ccc}
\hline $\begin{array}{c}\text { Peak } \\
\text { No. }\end{array}$ & $\begin{array}{c}\text { Wave number } \\
\left(\mathrm{cm}^{-1}\right)\end{array}$ & Tentative assignment \\
\hline 1 & 1368 & $\begin{array}{c}\text { Amide-III N-H in solid state also for water absorption and H-bonding } \\
2\end{array}$ \\
1575 & $\mathrm{RCO}_{2}^{-}, \mathrm{N}-\mathrm{H}$ bending for secondary Amide-II in solid state \\
3 & 1688 & Amide-I \\
4 and 5 & $2900-3100$ & Aliphatic and Aromatic C-H stretching \\
6 & $3100-3600$ & Broad band for O-H stretching N-H stretching and H-bonding \\
\hline
\end{tabular}

AFM image (Figure 9) shows the topography of the surface of BGO sample. Its roughness value $(0.5 \mathrm{~nm})$ is higher, by an order of magnitude, than that of the GO sheets surface. The immobilized proteins are globular in nature and they are aggregated as shown in the image Figure 9. 


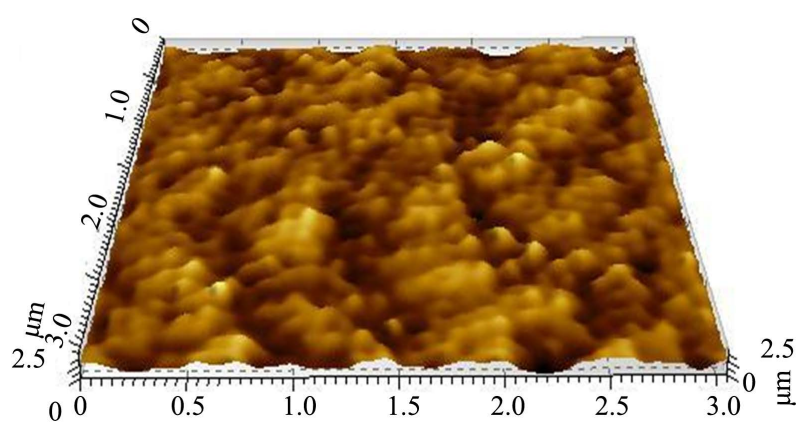

Figure 9. Non-contact mode 3D AFM topography images of BGO sheets: scan size $3 \mu \mathrm{m}$ $\times 3 \mu \mathrm{m}$.

\section{Conclusion}

We have demonstrated that GO films comprised of an ordered structure of carbon atoms can be prepared on large-area-substrate surfaces. We further demonstrated that GO is an atomically smooth substratum useful for protein immobilization. Good AFM imaging of BSA protein onto GO Sheet and retention of the conformation of the immobilized protein are due to the atomically smooth surface with roughness $<0.10 \mathrm{~nm}$. The ability to coat macroscopic surfaces presents GO Sheet as a potentially useful coating for biomedical devices, Spontaneous protein adsorption on Graphene Oxide nanosheets allowing efficient intracellular vaccine protein delivery [27]. HDLC materials have been shown to exhibit biocompatible surface properties [8] [9] [10]. It can be anticipated that GO sheet will also be biocompatible [9] [28] and may offer improved properties by harvesting [29] related to the highly ordered structure.

\section{Acknowledgements}

One (Hari Shankar Biswas) of the authors thank UGC Minor Project, Reference No.F.PSW-140/15-16 for funding. Authors also thank Mr. Biswarup Pal Choudhury, RKMVC College, Rahara, Dr. Susanta Debnath, SINP, Mr. U.S. Sil of PPD, SINP, Dr. Suchandra Chatterjee, Dr. Lalita Das, Department of Chemistry, Surendranath College, for characterization of sample and their technical help during the experiments in this work.

\section{Conflicts of Interest}

The authors declare no conflicts of interest regarding the publication of this paper.

\section{References}

[1] MacBeath, G. (2001) Proteomics Comes to the Surface. Nature Biotechnology, 19, 828-829. https://doi.org/10.1038/nbt0901-828

[2] Lee, H., Rho, J. and Messersmith, P.B. (2009) Facile Conjugation of Biomolecules onto Surfaces via Mussel Adhesive Protein Inspired Coatings. Advanced Materials, 21, 431-434. https://doi.org/10.1002/adma.200801222 
[3] Zhang, G. and Suggs, L. (2007) Matrices and Scaffolds for Drug Delivery in Vascular Tissue Engineering. Advanced Drug Delivery Reviews, 59, 360-373. https://doi.org/10.1016/j.addr.2007.03.018

[4] Hodneland, C.D., Lee, Y.D. and Mrksich, M. (2002) Selective Immobilization of Proteins to Self-Assembled Monolayers Presenting Active Site-Directed Capture Ligands. Proceedings of the National Academy of Sciences of the United States of America, 99, 5048-5052. https://doi.org/10.1073/pnas.072685299

[5] Elgamouz, A. and Tijani, N. (2018) Dataset in the Production of Composite Clay-Zeolite Membranes Made from Naturally Occurring Clay Minerals. Data in Brief, 19, 2267-2278. https://doi.org/10.1016/j.dib.2018.06.117

[6] Elgamouz, A., Tijani, N., Shehadi, I., Hasan, K. and Al-Farooq Kawam, M. (2019) Characterization of the Firing Behaviour of an Illite-Kaolinite Clay Mineral and Its Potential Use as Membrane Support. Heliyon, 5, e02281.

https://doi.org/10.1016/j.heliyon.2019.e02281

[7] Elgamouz, A., Idriss, H., Nassab, C., Bihi, A., Bajou, K., Hasan, K., Haija, M.A. and Patole, S.P. (2020) Green Synthesis, Characterization, Antimicrobial, Anti-Cancer, and Optimization of Colorimetric Sensing of Hydrogen Peroxide of Algae Extract Capped Silver Nanoparticles. Nanomaterials, 10, 1861.

https://doi.org/10.3390/nano10091861

[8] Tsang, S.C., Yu, C.H., Gao, X. and Tam, K. (2006) Silica-Encapsulated Nanomagnetic Particle as a New Recoverable Biocatalyst Carrier. The Journal of Physical Chemistry $B, 110,16914-16922$. https://doi.org/10.1021/jp062275s

[9] Zhang, J., Zhang, F., Yang, H., Huang, X., Liu, H., Zhang, J. and Guo, S. (2010) Graphene Oxide as a Matrix for Enzyme Immobilization. Langmuir, 26, 6083-6085. https://doi.org/10.1021/la904014z

[10] Tanum, J., Heo, J. and Hong, J. (2018) Spontaneous Biomacromolecule Absorption and Long-Term Release by Graphene Oxide. ACS Omega, 3, 5903-5909. https://doi.org/10.1021/acsomega.8b00537

[11] Biswas, H.S., Datta, J., Chowdhury, D.P., Reddy, A.V.R., et al. (2010) Covalent Immobilization of Protein onto a Functionalized Hydrogenated Diamond-Like Carbon Substrate. Langmuir, 26, 17413-17418. https://doi.org/10.1021/la103489g

[12] Ray, N.R., Datta, J., Biswas, H.S. and Datta, S. (2012) Signature of Misoriented Bilayer Graphenelike and Graphanelike Structure in the Hydrogenated Diamond-Like Carbon Film. IEEE Transactions on Plasma Science, 40, 1789-1793. https://doi.org/10.1109/TPS.2012.2201176

[13] Hummers, W.S. and Offeman, R.E. (1958) Preparation of Graphitic Oxide. Journal of the American Chemical Society, 80, 1339. https://doi.org/10.1021/ja01539a017

[14] Lotya, M., Hernandez, Y., King, P.J., Smith, R.J., Nicolosi, V. and Karlsson, L.S. (2009) Preparation and Characterization of Graphene Oxide Reduced from a Mild Chemical Method. Journal of the American Chemical Society, 131, 3611.

https://doi.org/10.1021/ja807449u

[15] Ferrari, A.C. and Robertson, J. (2000) Interpretation of Raman Spectra of Disordered and Amorphous Carbon. Physical Review B, 61, 14095-14107. https://doi.org/10.1103/PhysRevB.61.14095

[16] Wang, G.X., Wang, B., Park, J.S., Wang, Y., Sun, B. and Yao, J. (2009) Highly Efficient and Large-Scale Synthesis of Graphene by Electrolytic Exfoliation. Carbon, 47, 3242-3246. https://doi.org/10.1016/j.carbon.2009.07.040

[17] Layek, R.K., Ramakrishnan, K.R., Sarlin, E., Orell, O., Kanerva, M., Vuorinen, J. and Honkanen, M. (2018) Layered Structure Graphene Oxide/Methylcellulose Compo- 
sites with Enhanced Mechanical and Gas Barrier Properties. Journal of Materials Chemistry A, 6, 13203-13214. https://doi.org/10.1039/C8TA03651A

[18] Rajesh, R., Sujanthi, E., Kumar, S.S. and Venkatesan, R. (2015) Designing Versatile Heterogeneous Catalysts Based on Ag and Au Nanoparticles Decorated on Chitosan Functionalized Graphene Oxide. Physical Chemistry Chemical Physics, 17, 11329-11340. https://doi.org/10.1039/C5CP00682A

[19] Yang, Q., Pan, X., Clarke, K. and Li, K. (2011) Covalent Functionalization of Graphene with Polysaccharides. Industrial and Engineering Chemistry Research, 51, 310-317. https://doi.org/10.1021/ie201391e

[20] Stuart, B. (1997) Biological Applications of Infrared Spectroscopy. Wiley, London, 113-150.

[21] Kalsi, P.S. (2004) Spectroscopy of Organic Compounds. 6th Edition, New Age International, New Delhi, 65-177.

[22] Pavia, D.L., Lampman, G.M. and Kriz, G.S. (2009) Introduction to Spectroscopy. 4th Edition, Harcourt Brace and Company, Orlando, 30-76.

[23] Oliveira, S.F., et al. (2015) Protein Functionalized Carbon Nanomaterials for Biomedical Applications. Carbon, 95, 767-779. https://doi.org/10.1016/j.carbon.2015.08.076

[24] Calvo, P., Remunan-Lopez, C., Vila-Jato, J.L. and Alonso, M.J. (1997) Chitosan and Chitosan/Ethylene Oxide-Propylene Oxide Block Copolymer Nanoparticles as Novel Carriers for Proteins and Vaccines. Pharmaceutical Research, 14, 1431-1436. https://doi.org/10.1023/A:1012128907225

[25] He, H., Klinowski, J., Forster, M. and Lerf, A. (1998) A New Structure Model for Graphite Oxide. Chemical Physics Letters, 287, 53-56. https://doi.org/10.1016/S0009-2614(98)00144-4

[26] Lerf, A., He, H., Forster, M. and Klinowski, J. (1998) Structure of Graphite Oxide Revisited. The Journal of Physical Chemistry B, 102, 4477-4482. https://doi.org/10.1021/jp9731821

[27] Li, H., Fierens, K., Zhang, Z.y., Vanparijs, N., Schuijs, M.J., Van Steendam, K., Gracia, N.F., De Rycke, R., De Beer, T., De Beuckelaer, A., De Koker, S., Deforce, D., Albertazzi, L., Grooten, J., Lambrecht, B.N. and De Geest, B.G. (2016) Spontaneous Protein Adsorption on Graphene Oxide Nanosheets Allowing Efficient Intracellular Vaccine Protein Delivery. ACS Applied Materials \& Interfaces, 8, 1147-1155. https://doi.org/10.1021/acsami.5b08963

[28] Awaja, F., Tripathi, M., Coraça-Huber, D. and Speranza, I. (2018) Biocompatibility of Different Graphene Oxide Coatings on Polymers. Materialia, 2, 9-18. https://doi.org/10.1016/j.mtla.2018.08.009

[29] Brisebois, P.P. and Siaj, M. (2020) Harvesting Graphene Oxide-Years 1859 to 2019: A Review of Its Structure, Synthesis, Properties and Exfoliation. Journal of Material Chemistry C, 8, 10498-10525. https://doi.org/10.1039/C9TC03251G 